\title{
Progressive muscle relaxation technique on anxiety and depression among persons affected by leprosy
}

\author{
Senthilkumar Ramasamy', Suganya Panneerselvam² ${ }^{2}$ Pitchaimani Govindharaj], , Archana Kumar', Rashmi Nayak' \\ 'Bethasda Leprosy Mission Hospital, Champa, Chhattisgarh, India \\ ${ }^{2}$ All India Institute of Medical Sciences, Raipur, Chhattisgarh, India \\ ${ }^{3}$ The Leprosy Mission Hospital, Purulia, West Bengal, India
}

Anxiety and depression have been found to be increasing among people with leprosy and it may lead to decreased social participation. The progressive muscle relaxation technique (PMRT) is widely used today in choice of treatment for reducing the anxiety and depression. This study aimed to assess the effectiveness of PMRT in reducing anxiety and depression among the hospitalized leprosy affected person in a tertiary care centre. This study is a case series of 50 leprosy affected people aged between 18-60 years who were admitted for leprosy complications in tertiary leprosy referral hospital. The Anxiety-Depression scale was developed and validated by the investigators and administered before intervention of PMRT and after 2 weeks. The follow-up assessment was done at 6 weeks after the initial intervention. The finding shows that a statistically significant difference was observed on anxiety domain before and after application of PMRT. The anxiety means score showed steady decline from 6.76 at pretest to $3.0(t=25.068, P \leq 0.001)$ at post test and $1.12(t=22.679, P \leq 0.001)$ at follow-up. In depression domain, a statistically significant difference was seen in before and after application of PMRT. The depression means score showed steady decline from 6.92 at pre test to $3.28(t=16.082, P \leq 0.001)$ at post test and to $1.16(t=18.918, P \leq 0.001)$ at follow-up. This study proved that the PMRT as a valid treatment option for hospitalized person with leprosy in minimizing the anxiety and depression related symptoms and to benefit the psychosocial wellbeing of leprosy affected patients.

Keywords: Leprosy, Progressive muscle relaxation, Anxiety, Depression

\section{INTRODUCTION}

Hospitalization is a stressful and threatening experience (Li et al., 2016). Patients admitted for leprosy complications often suffer from painful physical and mental symptoms. This is reflected on their reluctance and delay in seeking hospitalization and also it generates great anxiety while admitted as inpatients (George et al., 2013). Depression and anxiety symptoms increased from the time of admission toward longer hospital stay (Shoar et al., 2016). Studies show that, up to $50 \%$ the people affected by leprosy will face depression, anxiety and even have thoughts of suicide (Lepra, 2017). This anxiety and depression may lead to decreased social participation and social exclusion among leprosy affected person (Adhikari et al., 2014).

Anxiety disorders have been found to be increasing among peo- ple with leprosy. It is suggested that it creates tension, irritation, anger and worries (Chauhan et al., 1983). A study reported, all responses experienced anxiety while admitted at a hospital and the majority felt that lengthy institutionalization had more disadvantages than advantages (Scott, 2000).

Depression is more than just sadness. According to the American psychological association (2018), people with depression may experience a lack of interest and pleasure in daily activities, significant weight loss or gain, insomnia or excessive sleeping, lack of energy, inability to concentrate, feelings of worthlessness or excessive guilt and recurrent thoughts of death or suicide. Studies are reported depression is the most common psychiatric disorder among leprosy patients (Kisivuli et al., 2005; Kumar and Verghese, 1980; Sentürk and Sağduyu, 2004). According to the World Health Organization (WHO), if we not take immediate

\footnotetext{
${ }^{*}$ Corresponding author: Pitchaimani Govindharaj

(iD) https://orcid.org/0000-0002-3637-3760

Research Scholar, Department of Sociology, Bharathidasan, University,

Tiruchirappalli, Tamil Nadu-620024, India

Tel: +91-9800940029, E-mail: pitchu_mani83@yahoo.com

Received: March 21, 2018 / Accepted: April 22, 2018
} 
act on depression, it will result the leading illness globally by 2030 (WHO, 2017).

Relaxation has a significant psychological impact. Through relaxation we can improve specific aspects of our personality, strengthening the positive qualities and changing unwanted habits and attitudes (Kumar et al., 2015). Edmund Jacobson invented the progressive muscle relaxation technique (PMRT) in the 1920s as a way to help patients to deal with anxiety and he felt that relaxing the muscles could relax the mind as well (Kisner and Colby, 2007). The progressive muscle relaxation technique is easily learned and widely used today as a choice of treatment for reducing the anxiety and depression. Hence, the study aim to assess the effectiveness of progressive muscle relaxation technique in reducing anxiety and depression among the hospitalized leprosy affected person in a tertiary care centre.

\section{MATERIALS AND METHODS}

A prospective open-label single arm study conducted with 50 leprosy affected people who were admitted for leprosy complications during the period of March to August, 2016 in a tertiary leprosy referral hospital.

\section{Inclusion and exclusion criteria}

The study includes those aged between 18-60 years, who were willing to participate in the study and able to understand relaxation techniques. Those patients who were practicing other relaxation technique such as yoga and/or on meditation for anxiety or depression were excluded from the study. Those who are alcohol dependence, tobacco chewers and/or smokers were also excluded as they may directly affect psychological status of an individual.

\section{Semistructured questionnaire}

A semistructured questionnaire was used to interview the participants and it consists details of disease profile, clinical profile, and demographic profile.

\section{Anxiety and depression scale}

Most of the standardized scales of anxiety and depression are available in self-administered model, and it is not suitable for the hospitalized leprosy affected people, as the leprosy affects mostly poor and illiterate people. Hence, the researcher developed a set of questionnaires for face-to-face interview, with the reference from Hospital anxiety depression scale (Zigmond and Snaith, 1983), Beck depression inventory (Beck et al., 1961), Beck anxiety inven- tory (Beck et al., 1988), and Hamilton anxiety scale (Hamilton, 1959). It consists of 10 items questionnaire in a 4-point likert scale ( 0 , never; 1 , sometimes; 2 , most of the times; and 3 , always) in two domains ( 5 items each in anxiety and depression). Each domain of anxiety and depression scores range from 0 to 15, the higher level of score indicates that more anxiety and depression.

The scale translation procedure was followed as per WHO guidelines (WHO, 2007). The content and face validity were done for scale items by three expertise who experienced in leprosy treatment and rehabilitation. The study was carried out in a manner to ensure the clarity of questions to patients and conducted a reliability test for internal consistency of the questionnaires.

\section{Reliability}

The Hindi version of the scale was tested in the community and studied for internal consistency and reliability. The Cronbach alpha score was 0.865 for 10 items scale of Anxiety-Depression scale. The domain Cronbach alpha score was, 0.80 for anxiety (5 items) and 0.77 for depression ( 5 items). The corrected item-total correlation ranged from 0.43 to 0.83 , with 7 items falling at or above 0.50 . The Cronbach alpha scores for the scale of each individual item deleted ranged from 0.83 to 0.87 . A statistical significant positive relationship was found between anxiety domain and depression domain $(r=0.68, P=0.00)$.

\section{Intervention of PMRT}

Jacobsen progressive muscle relaxation technique was demonstrated and taught after ensuring that the participants understood about the technique.

Sequence of progressive muscle relaxation techniques:

- Make them in a comfortable position (preferably sitting)

-While beginning to tense the muscle group, asked the patient to feel the tension, but not so much that deal of pain. Keep the muscle tensed for approximately $5 \mathrm{sec}$

- Relax the muscles and keep it relaxed for approximately 10 to $15 \mathrm{sec}$

Followed by instruction, relaxation sequences were demonstrated to the patients in three steps as showed in Table 1. In first and third steps of the relaxation sequence, the patients were advised to begin the technique from right side of the body followed by left side.

\section{Procedure}

Author arranged a convenient place in in-patient department to demonstrate the PMRT. After participants become familiar with performing this PMRT, they were asked to perform it according 
Table 1. Relaxation sequence demonstrated to patients

\begin{tabular}{|c|c|c|}
\hline \multirow{2}{*}{ Step } & \multicolumn{2}{|r|}{ Progressive muscles relaxation technique } \\
\hline & Parts & Exercise \\
\hline \multirow[t]{2}{*}{1} & Hand \& forearm & Make a fist with your hand \\
\hline & Upper arm & $\begin{array}{l}\text { Bring your right forearm up to your shoulder to "make } \\
\text { a muscle" }\end{array}$ \\
\hline \multirow[t]{8}{*}{2} & Forehead & $\begin{array}{l}\text { Raise your eyebrows as high as they will go, as } \\
\text { though you were surprised by something }\end{array}$ \\
\hline & Eyes and cheeks & Squeeze your eyes tight shut \\
\hline & Mouth and jaw & $\begin{array}{l}\text { Open your mouth as wide as you can, as you might } \\
\text { when you're yawning }\end{array}$ \\
\hline & Neck & $\begin{array}{l}\text { Be careful as you tense these muscles. Face forward } \\
\text { and then pull your head back slowly, as though you } \\
\text { are looking up to the ceiling }\end{array}$ \\
\hline & Shoulders & $\begin{array}{l}\text { Tense the muscles in your shoulders as you bring your } \\
\text { shoulders up towards your ears }\end{array}$ \\
\hline & $\begin{array}{l}\text { Shoulder blades/ } \\
\text { back }\end{array}$ & $\begin{array}{l}\text { Push your shoulder blades back, trying to almost touch } \\
\text { them together, so that your chest is pushed forward }\end{array}$ \\
\hline & Chest and stomach & $\begin{array}{l}\text { Breathe in deeply, filling up your lungs and chest with } \\
\text { air }\end{array}$ \\
\hline & Hips and buttocks & Squeeze your buttock muscles \\
\hline \multirow[t]{3}{*}{3} & Upper leg & Tighten your thigh \\
\hline & Lower leg & $\begin{array}{l}\text { Do this slowly and carefully to avoid cramps. Pull your } \\
\text { toes towards you to stretch the calf muscle }\end{array}$ \\
\hline & Foot & Curl your toes downwards \\
\hline
\end{tabular}

to their choice of individual or in a group; twice in a day for 5-6 days a week under supervision of the physiotherapist during hospitalization. In a day, two sessions were conducted in the morning and evening approximately for $30 \mathrm{~min}$. The anxiety-depression scale assessment was first administered at the time of admission and repeated after 2 weeks. Patients were instructed to continue the same technique and follow-up assessment were done in 6 weeks after the initial intervention. When patients were discharged at any time during the study period, they were requested to continue the techniques at home and given an appointment for follow-up assessment.

Informed consent was taken prior to inclusion in the study from each individual participant. All the collected information about patient was kept confidential. Collected data were entered and analyzed in statistical software of IBM SPSS Statistics ver. 23.0 (IBM Co., Armonk, NY, USA).

\section{RESULTS}

A total of 50 subjects who are aged between from 18 to 60 years were undergone PMRT during the study period, out of all participants $36(72 \%)$ were males. Thirty-six of the participants (72\%) was admitted for the first time for treatment for leprosy and 39
Table 2. Demographic and disease profile of the participants $(n=50)$

\begin{tabular}{|c|c|}
\hline Demographic status & No. $(\%)$ \\
\hline \multicolumn{2}{|l|}{ Gender } \\
\hline Male & $36(72)$ \\
\hline Female & $14(28)$ \\
\hline \multicolumn{2}{|l|}{ Age (yr) } \\
\hline $18-30$ & $24(48)$ \\
\hline $31-45$ & $13(26)$ \\
\hline $46-60$ & $13(26)$ \\
\hline \multicolumn{2}{|l|}{ Education } \\
\hline Primary & $9(18)$ \\
\hline Secondary & $16(32)$ \\
\hline Higher secondary & $9(18)$ \\
\hline No education & $16(32)$ \\
\hline \multicolumn{2}{|l|}{ Occupation } \\
\hline Farmer & $15(30)$ \\
\hline Labor & $10(20)$ \\
\hline Skilled labor & $11(22)$ \\
\hline Professional \& small business & $8(16)$ \\
\hline House wife & $6(12)$ \\
\hline \multicolumn{2}{|l|}{ Treatment status } \\
\hline New & $11(22)$ \\
\hline Under treatment & $28(56)$ \\
\hline Released from treatment & $11(22)$ \\
\hline \multicolumn{2}{|l|}{ WHO disability grade } \\
\hline Grade 0 & $9(18)$ \\
\hline Grade 1 & $13(26)$ \\
\hline Grade 2 & $28(56)$ \\
\hline \multicolumn{2}{|l|}{ Reason for admission } \\
\hline Neuritis & $18(36)$ \\
\hline Reaction and neuritis & $20(40)$ \\
\hline Ulcer & $12(24)$ \\
\hline \multicolumn{2}{|l|}{ Number of time admission } \\
\hline First time & $36(72)$ \\
\hline Second time & $9(18)$ \\
\hline Third time and above & $5(10)$ \\
\hline
\end{tabular}

WHO, World Health Organization.

(78\%) were on multidrug therapy, of this 11 were newly diagnosed case of leprosy and 28 of the participants $(56 \%)$ had grade 2 disabilities. Thirty-eight participants had recent history of lepra reaction and/or neuritis and all of them were under steroid therapy. The demographic and disease profiles are shown in Table 2.

\section{Descriptive analysis for anxiety-depression scale for variables}

In anxiety-depression scale, the scores of the single items were summed and divided by the total number of items (5) for each domain (anxiety and depression). The higher mean score indicates that, the more anxiety and depression on person affected with leprosy. 
The female had higher mean score on domains of anxiety and depression when compared with male. The patients aged with 45-60 years had a higher mean score than $18-30$ years and 31-45 years in the domains of anxiety and depression. The participants who were not attained formal education had higher mean score in

Table 3. Descriptive analysis for anxiety-depression scale for variables before progressive muscle relaxation technique $(n=50)$

\begin{tabular}{|c|c|c|c|}
\hline Variable & No. & Anxiety & Depression \\
\hline \multicolumn{4}{|l|}{ Gender } \\
\hline Male & 36 & $6.19 \pm 2.45(2-12)$ & $6.42 \pm 2.74(1-13)$ \\
\hline Female & 14 & $8.21 \pm 3.04(5-12)$ & $8.21 \pm 3.02(4-13)$ \\
\hline \multicolumn{4}{|l|}{ Age (yr) } \\
\hline $18-30$ & 24 & $6.63 \pm 2.86(2-12)$ & $6.75 \pm 2.40(3-13)$ \\
\hline $31-45$ & 13 & $6.46 \pm 2.07(5-12)$ & $6.00 \pm 2.92(2-13)$ \\
\hline $46-60$ & 13 & $7.31 \pm 3.25(2-12)$ & $8.15 \pm 3.51(1-13)$ \\
\hline \multicolumn{4}{|l|}{ Education } \\
\hline Primary & 9 & $6.78 \pm 2.91(2-10)$ & $6.67 \pm 3.571-11)$ \\
\hline Secondary & 16 & $5.56 \pm 2.00(2-11)$ & $6.56 \pm 2.73(3-13)$ \\
\hline Higher secondary & 9 & $6.89 \pm 2.76(3-12)$ & $6.33 \pm 2.35(2-9)$ \\
\hline No education & 16 & $7.88 \pm 3.05(3-12)$ & $7.75 \pm 3.04(4-13)$ \\
\hline \multicolumn{4}{|l|}{ Treatment status } \\
\hline New & 11 & $6.09 \pm 3.18(2-12)$ & $5.55 \pm 1.13(4-7)$ \\
\hline Under treatment & 28 & $6.89 \pm 2.60(2-12)$ & $7.07 \pm 3.23(1-13)$ \\
\hline Released from treatment & 11 & $7.09 \pm 2.84(3-12)$ & $7.91 \pm 2.95(4-13)$ \\
\hline \multicolumn{4}{|l|}{ Disability status } \\
\hline Grade 0 & 9 & $6.11 \pm 2.67(2-11)$ & $6.00 \pm 2.69(1-10)$ \\
\hline Grade 1 & 13 & $6.62 \pm 2.87(3-12)$ & $7.38 \pm 3.45(3-13)$ \\
\hline Grade 2 & 28 & $7.04 \pm 2.78(2-12)$ & $7.00 \pm 2.74(2-13)$ \\
\hline \multicolumn{4}{|l|}{ Reason for admission } \\
\hline Neuritis & 18 & $6.00 \pm 2.45(3-12)$ & $6.00 \pm 2.68(2-13)$ \\
\hline T1 reaction & 11 & $5.91 \pm 2.51(2-11)$ & $5.91 \pm 2.91(1-11)$ \\
\hline T2 reaction & 9 & $8.33 \pm 2.24(6-12)$ & $8.44 \pm 2.30(6-13)$ \\
\hline Ulcer & 12 & $7.50 \pm 3.29(2-12)$ & $8.08 \pm 3.03(4-13)$ \\
\hline \multicolumn{4}{|l|}{ Number of admission time } \\
\hline First time & 36 & $6.44 \pm 2.84(2-12)$ & $6.42 \pm 2.96(1-13)$ \\
\hline Second time & 9 & $7.67 \pm 2.96(5-12)$ & $8.22 \pm 2.95(5-12)$ \\
\hline Third time and above & 5 & $7.40 \pm 1.14(6-9)$ & $8.20 \pm 1.10(7-10)$ \\
\hline
\end{tabular}

Values are presented as mean \pm standard deviation (range). both the domains than the attained formal education. Those who had completed multidrug therapy had higher mean score than those who are under multidrug therapy. It was found that persons with grade 2 disabilities had a higher mean score in anxiety domain, whereas the person with grade 1 disabilities had higher mean score in depression domain. In association with neuritis and type 1 lepra reaction, the type 2 lepra reaction and ulcer patients had higher mean score on both the domains. The mean score were higher for those who were admitted in the hospital for more than one time (Table 3).

\section{A significant difference for before and after PMRT on anxiety and depression}

\section{Anxiety}

A statistically significant difference was seen on anxiety before and after application of PMR techniques. The anxiety means score showed steady decline from 6.76 at pretest to $3.0(t=25.068, P \leq$ $0.001)$ at posttest and $1.12(t=22.679, P \leq 0.001)$ at final follow-up.

\section{Depression}

A statistically significant difference was seen on depression before and after application of PMR technique. The depression means score showed steady decline from 6.92 at pretest to 3.28 $(t=16.082, P \leq 0.001)$ at posttest and to $1.16(t=18.918, P \leq$ 0.001 ) at final follow-up (Table 4).

\section{DISCUSSION}

In our knowledge, this was the first study in leprosy which used PMRT to reduce anxiety and depression among hospitalized persons. PMRT is the choice of relaxation therapy to reduce anxiety and depression disorders used in most of the chronic disease (Stoppler, 2014). Past research showed, anxiety related symptoms improved after the use of PMRT (Redd et al., 2001; Burish and Tope, 1992). Studies from India showed PMRT are effective in re-

Table 4. Paired $t$-test for before and after application of progression muscle relaxation technique $(n=50)$

\begin{tabular}{|c|c|c|c|c|c|c|}
\hline Status & Pretest & Posttest & Follow-up & Paired t-test & $t$-value & $P$-value \\
\hline \multirow[t]{2}{*}{ Anxiety } & $6.76 \pm 2.75$ & $3.00 \pm 2.63$ & $1.12 \pm 1.51$ & Pre- vs. Posttest & 25.07 & $0.000^{*}$ \\
\hline & & & & Pretest vs. follow-up & 22.68 & $0.000^{*}$ \\
\hline \multirow[t]{2}{*}{ Depression } & $6.92 \pm 2.91$ & $3.28 \pm 2.59$ & $1.16 \pm 1.53$ & Pre- vs. Posttest & 16.08 & $0.000^{*}$ \\
\hline & & & & Pretest vs. follow-up & 18.92 & $0.000^{*}$ \\
\hline
\end{tabular}

Values are presented as mean \pm standard deviation.

${ }^{*} P<0.05$, statistically significant difference. 
ducing anxiety among people affected with psychological disorders (Ranjita and Sarada, 2014), reducing the level of stress among the geriatric patient with psychotic illness (Ramakrishnan and Kalai Chandran, 2015), and reducing the physical symptoms due to chemotherapy in cancer patients receiving chemotherapy (Gupta et al., 2016). In this study, pretest versus posttest and follow-up test showed a statistically significant steady decline of anxiety and depression among those admitted for leprosy complication.

A study from Bangladesh found, depressive status in leprosy patients was greater than that of general public (Tsutsumi et al., 2004). A comparative study from Ethiopia, showed that mental distress was significantly higher in patients with leprosy compared to patients with other dermatological conditions (Leekassa et al., 2004). Bhatia et al. (2006), done a study on psychiatric morbidity and pattern of dysfunction in patients with leprosy showed that the predominant psychiatric illness in study group was generalized anxiety disorder (27.8\%) and mixed anxiety and depressive disorder (13.3\%). In this study, the initial assessment before the start of PMRT showed that $42 \%$ had moderate sum score from 6 to 10 and 12\% had higher sum score (above 10) in anxiety domain. In depression domain, $50 \%$ had moderate sum score from 6 to 10 and $14 \%$ had higher sum score (above 10), which is comparable to their findings.

A study on women with leprosy showed that anxiety disorders were more commonly found in women (Morrison, 2000). A study from India done by Yaduvanshi et al. (2016), revealed that the female leprosy affected patient had significantly more depression than male patients. A study from Ethiopia done by Leekassa et al. (2004), found a higher prevalence of mental distress in female leprosy patients than males which was significantly associated with disability. In this study, female patients had a statistically significant higher mean score in anxiety-depression scale than the male patients after their admission in hospital for treatment of complications due to leprosy.

Elder patients and those who have not attained any formal education patients had higher mean score in anxiety and depression domain than younger patients and attained formal education patients, respectively. It is not surprising that not attained formal education patients had higher mean score in anxiety and depression domain, which may be due to their lack of knowledge and awareness about the disease. However, the improvement in anxiety and depression was observed across age group and level of education.

Reis et al. (2014), found a higher prevalence of psychological distress in leprosy patients with higher disability levels, further patients with psychological distress had the lowest quality of life. In this study, the participant who had grade 2 disabilities found to have more anxiety than those with grade 1 or no disability, while the depression levels was higher among those with grade 1 disability. Although the persons admitted for type 2 lepra reaction and plantar ulcers had higher mean score as compared to persons admitted for neuritis and type 1 lepra reaction. This is probably due to need a longer hospitalization for type 2 lepra reaction and plantar ulcers.

Early detection and treatment of psychiatric disorders among leprosy affected patients is a powerful psychotherapeutic measure (Singh, 2012). In this study a statistically significant relationship was found between domains of anxiety and depression, suggesting that hospitalized patients are prone to develop anxiety and depressive disorder. The PMRT helps in reducing their symptoms. Moreover, this relaxation therapy is easy to learn and practice, does not require trained professional or any equipment to facilitate the training and is cost effective. This study proved as a valid treatment option for hospitalized person with leprosy to minimize the anxiety and depression related disorders among them.

Manzoni et al. (2008), conducted a systemic review and examined anxiety level before and after relaxation training for reduction of anxiety both in clinical and nonclinical population. It is found that many studies shown a positive clinical outcome after the relaxation techniques in connection with anxiety.

This study had few limitations. This study involved the small sample of person with leprosy hospitalized for their illness and there was no control group to compare the outcome. It has to be noted that the study participants are those admitted for complications due to leprosy, and often come from far away distance. It is very difficult to ascertain whether the observed anxiety and depression is due to complications of leprosy or prolonged hospitalization or both. Future studies will need to investigate the Anxiety-Depression scale test-retest reliability and need cross cultural validation of the scale.

In summary, the PMRT is effective relaxation therapy to reduce the anxiety and depression among hospitalized person with leprosy. This relaxation therapy is easy to learn and practice, does not require trained professional or any equipment to facilitate the training. This study proved as a valid treatment option for hospitalized person with leprosy in minimizing the anxiety and depression related symptoms and to benefit the psychosocial well-being of leprosy affected patients. 


\section{CONFLICT OF INTEREST}

No potential conflict of interest relevant to this article was reported.

\section{REFERENCES}

Adhikari B, Kaehler N, Chapman RS, Raut S, Roche P. Factors affecting perceived stigma in leprosy affected persons in western Nepal. PLoS Negl Trop Dis 2014;8:e2940.

American Psychological Association. Depression [Internet]. Washington, DC: American Psychological Association; 2018 [cited 2017 Aug 3]. Available from: http://www.apa.org/topics/depression/.

Beck AT, Epstein N, Brown G, Steer RA. An inventory for measuring clinical anxiety: psychometric properties. J Consult Clin Psychol 1988;56: 893-897.

Beck AT, Ward CH, Mendelson M, Mock J, Erbaugh J. An inventory for measuring depression. Arch Gen Psychiatry 1961;4:561-571.

Bhatia MS, Chandra R, Bhattacharya SN, Imran M. Psychiatric morbidity and pattern of dysfunction in patients with leprosy. Indian J Dermatol 2006;51:23-25.

Burish TG, Tope DM. Psychological techniques for controlling the adverse side effects of cancer chemotherapy: findings from a decade of research. J Pain Symptom Manage 1992;7:287-301.

Chauhan NS, Dhar U, Chauhan S. 'Frustration--anxiety behaviour as a function of leprosy patients age and personality'. Lepr India 1983;55: 743-751.

George A, Khora T, Das P, Rao PS. Nursing interventions to manage anxiety levels of female inpatients admitted first time in a leprosy hospital. Indian J Lepr 2013;85:19-25.

Gupta B, Kumari M, Kaur T. Effectiveness of progressive muscle relaxation technique on physical symptoms among patients receiving chemotherapy. Nurs Midwifery Res J 2016;12:33-40.

Hamilton M. The assessment of anxiety states by rating. Br J Med Psychol 1959;32:50-55

Kisivuli AJ, Othieno CJ, Mburu JM, Kathuku DM, Obondo A, Nasokho PW. Psychiatric morbidity among leprosy patients in Teso and Busia districts of Western Kenya. East Afr Med J 2005;82:452-456.

Kisner C, Colby LA. Therapeutic exercise: foundations and techniques. 5th ed. Philadelphia (PA): F.A. Davis Company; 2007.

Kumar JH, Verghese A. Psychiatric disturbances among leprosy patients. An epidemiological study. Int J Lepr Other Mycobact Dis 1980;48:431434.

Kumar S, Nayak RR, Devi SK. Effectiveness Jacobson's progressive muscle relaxation technique (PMRT) to relieve anxiety among alcoholic patients MHI, SCB, Cuttack, Odisha. J Nurs Health Sci 2015;4:1-6.

Leekassa R, Bizuneh E, Alem A. Prevalence of mental distress in the outpatient clinic of a specialized leprosy hospital. Addis Ababa, Ethiopia, 2002. Lepr Rev 2004;75:367-375.

Lepra. Helping people affected by leprosy to overcome depression [Internet]. Colchester (UK): Lepra; 2017 [cited 2017 Aug 3]. Available from: https://www.lepra.org.uk/news/helping-people-affected-by-leprosyovercome-depression.

Li WH Chung JO, Ho KY, Kwok BM. Play interventions to reduce anxiety and negative emotions in hospitalized children. BMC Pediatr 2016;16: 36.

Manzoni GM, Pagnini F, Castelnuovo G, Molinari E. Relaxation training for anxiety: a ten-years systematic review with meta-analysis. BMC Psychiatry 2008;8:41.

Morrison A. A woman with leprosy is in double jeopardy. Lepr Rev 2000; 71:128-143.

Ramakrishnan M, Kalai Chandran K. The effects of progressive muscular relaxation exercise among geriatric patients with psychiatric illness. Int J Sci Res 2015;4:963-966.

Ranjita L, Sarada N. Progressive muscle relaxation therapy in anxiety: a neurophysiological study. J Dent Med Sci 2014;13:25-28.

Redd WH, Montgomery GH, DuHamel KN. Behavioral intervention for cancer treatment side effects. J Natl Cancer Inst 2001;93:810-823.

Reis FJ, Lopes D, Rodrigues J, Gosling AP, Gomes MK. Psychological distress and quality of life in leprosy patients with neuropathic pain. Lepr Rev 2014;85:186-193.

Scott J. The psychosocial needs of leprosy patients. Lepr Rev 2000;71:486491.

Sentürk V, Sağduyu A. Psychiatric disorders and disability among leprosy patients; a review. Turk Psikiyatri Derg 2004;15:236-243.

Shoar S, Naderan M, Aghajani M, Sahimi-Izadian E, Hosseini-Araghi N, Khorgami Z. Prevalence and determinants of depression and anxiety symptoms in surgical patients. Oman Med J 2016;31:176-181.

Singh GP. Psychosocial aspects of Hansen's disease (leprosy). Indian Dermatol Online J 2012;3:166-170.

Stoppler M. Progressive muscle relaxation for stress and insomnia [Internet]. Medicine Net; 2014 [cited 2017 Jul 14]. Available from: http:// www.medicinenet.com/script/main/art.asp?articlekey=47281.

Tsutsumi A, Izutsu T, Akramul Islam MD, Amed JU, Nakahara S, Takagi F, Wakai S. Depressive status of leprosy patients in Bangladesh: association with self-perception of stigma. Lepr Rev 2004;75:57-66.

World Health Organization. Depression [Internet]. Geneva (Switzerland): World Health Organization; 2017 [cited 2017 Aug 8]. Available from: http://www.who.int/mediacentre/factsheets/fs369/en/.

World Health Organization. Process of translation and adaptation of 
instruments [Internet]. Geneva (Switzerland): WHO; 2007 [cited 2017 Aug 8]. Available from: http://www.who.int/substance_abuse/ research_tools/translation/en/.

Yaduvanshi AK, Abraham A, Jain S, Tomar S. A study of 298 psychologi- cal correlates in leprosy patients of Agra and Kanpur district. Indian J Health Wellbeing 2016;7:319-322.

Zigmond AS, Snaith RP. The hospital anxiety and depression scale. Acta Psychiatr Scand 1983;67:361-370. 